\title{
Organizações Totalitárias: Modus Operandi e Fundamentos
}

\author{
Totalitarian Organizations: Modus Operandi and Fundamentals
}

Universidade Tecnológica Federal do Paraná, Programa de Pós-Graduação em Administração, Programa de PósGraduação em Tecnologia e Sociedade, Curitiba, PR, Brasil ${ }^{1}$

Artigo recebido em 10.11.2017. Última versão recebida em 22.09.2018. Aprovado em 24.10.2018. 


\title{
Resumo
}

Este ensaio é resultado de reflexões decorrentes de dez anos de estudos realizados a partir da análise histórica das seguintes organizações: os Einsatzgruppen, o complexo de Auschwitz e os campos de extermínio da Operação Reinhard - Sobibór, Belzec e Treblinka, que compuseram o Estado Nazista; as organizações terroristas Al-Qaeda e Estado Islâmico, com presença em diversos países por meio de redes de células cooperativas. Essas organizações foram ou são atuantes no contexto da modernidade, sendo caracterizadas pela prevalência da reprodução sociometabólica do capital e da instituição da racionalidade instrumental. As organizações totalitárias caracterizam-se por possuírem modi operandi próprios na forma como promovem os assassinatos e os extermínios sistemáticos e planejados de pessoas, geralmente antecedidos pela adoção de práticas de violência. Apesar dessas particularidades, todas elas têm como fundamento o estabelecimento de uma política de terror social, a prática da aniquilação do humano e a instituição do mal.

Palavras-chave: organizações totalitárias; extermínio; terror social; aniquilação do humano; mal.

\begin{abstract}
This essay is the outcome of reflections based on a ten-year study conducted from historical analysis about the Einsatzgruppen, the Auschwitz complex, and the extermination camp of Operation Reinhard - Sobibór, Belzec, Treblinka, all of which made up the Nazi State, and terrorist organizations such as Al-Qaeda and ISIS, present in several countries through a networking of cooperative cells. These organizations have been active in the context of the Modernity Era, characterized by the prevalence of capital sociometabolic reproduction and the institution of instrumental rationality. The totalitarian organizations have their own modus operandi in promoting murder and the systematic and planned annihilation of people, generally preceded by the use of violence. Despite these singularities, they all fundamentally aim to establish a policy of social terror, practice human annihilation, and foster the institution of evil.
\end{abstract}

Keywords: totalitarian organizations; extermination; social terror; human annihilation; evil.

JEL code: B15, K14, D72. 


\section{Introdução}

De forma geral, as religiões, os modos de produção e as ideologias pregam a vida como sendo um valor em si mesmo. Entretanto, vida e morte, criação e destruição, ainda que antagônicos, são valores indissociáveis que se revelam presentes ao longo de toda a história da humanidade. Segundo Freud (1976, 1980, 1997), em suas obras sociais, a violência é, também, parte constitutiva da sociedade. Esta, inclusive, foi fundada por um ato criminoso: o assassinato do pai por seus filhos (Freud, 1976). Dessa forma, desde os seus primórdios, a humanidade vive uma tensão entre civilização e barbárie (Novaes, 2004), o que pode ser verificado a partir da constatação dos maiores conflitos, guerras, extermínios e genocídios experimentados em todos os períodos históricos (Charny, 1982; White, 2013). Assim, é possível afirmar que a história da humanidade é, em grande medida, a história da barbárie.

Na modernidade, com o advento e a consolidação do sistema de capital (Mészáros, 2015) e das ciências como força produtiva, a base técnico-científica que organiza a vida social passou a fomentar situações contraditórias no processo civilizatório. Por um lado, enseja a constituição de uma sociedade que transforma o capitalismo em uma religião (Benjamin, 2015), ou seja, na forma estruturante de todas as dimensões da vida dos sujeitos ao mesmo tempo em que consolida a autoridade racional-legal como a dominante. Assim, institui os estados nacionais como uma superestrutura que organiza e controla a vida social. De outro lado, como em qualquer processo dialético, cria e fomenta focos e formas de resistência às tendências de dominação que se apresentam como totalizadoras, como é o caso do sistema de capital de base técnica organizado a partir do avanço das ciências.

De qualquer forma, a modernidade não foi capaz de extinguir e nem ao menos diminuir a barbárie como ente permanente e presente na organização da vida social. Nela, a barbárie incorpora à eficiência da produção em massa algo que o sistema produtivo de capital, associado às ciências como força produtiva, conseguiu desenvolver. A modernidade mudou a percepção que se tinha da relação de oposição entre civilização e barbárie (Henry, 2012; Mattéi, 2002; Wolff, 2004), demonstrando que essa relação é, na realidade, indissociável e permanente. Assim, a modernidade não inventou a barbárie, mas a levou ao extremo com os diversos exemplos de genocídios que ocorreram durante seu período (Charny, 1998; Gellately \& Kiernan, 2013; Stivelman \& Stivelman, 2001; Yürükel, 2004). Diferente da concepção de organizações totais, proposta por Goffman (2010), que não têm como finalidade a eliminação dos sujeitos que as constituem, na modernidade, surgem as organizações totalitárias, que têm como objetivo per se o extermínio sistemático de pessoas. Os dez anos de leituras, estudos, pesquisas e análises dessas organizações permitem a apresentação deste ensaio, que tem por objetivo analisar e refletir acerca do contexto geral em que surgem e no qual se inserem, o modus operandi e os fundamentos das organizações totalitárias.

As organizações analisadas e que dão subsídios analíticos para este ensaio são:

1) Os Einsatzgruppen, conhecidos como forças tarefas ou grupos de intervenção, que tinham o propósito de exterminar pessoas em países do leste europeu. Atuavam como organizações independentes que agiam para colocar em prática a aniquilação dos inimigos do regime nazista. Sua atuação ganhou força sobretudo após a Operação Barbarossa, em junho de 1941, quando houve a invasão da União Soviética por parte da Alemanha nazista. Estima-se que foram responsáveis pelo extermínio de mais de um milhão e trezentas mil pessoas, sobretudo por fuzilamento (Arad \& Krakowski, 1989; Rhodes, 2003).

2) O complexo do campo de concentração de Auschwitz, exemplo de como pode funcionar uma máquina de extermínio sob a administração de um estado totalitário, conforme a concepção de Arendt (2013). Sua estrutura era formada por uma série de campos e subcampos (Gutman \& Berenbaum, 1998; Piper \& Swiebocka, 1996) associados entre si e que tinham funções especializadas, como a produção de armamentos para o exército alemão, a produção de produtos para organizações privadas, o extermínio em massa de judeus, ciganos, polacos, inimigos do regime nazista etc., além da adoção de uma política de extermínio por meio do trabalho forçado 
(Allen, 2005; Gutman \& Berenbaum, 1998; Piper \& Swiebocka, 1996). Auschwitz I era a área do campo de concentração. Auschwitz II-Birkenau a área especializada no extermínio em massa e Auschwitz III-Monowitz a de produção industrial que se utilizava mão-de-obra escrava. O complexo também serviu como laboratório para o aprimoramento da ciência nazista, que funcionava sem qualquer limite ético na utilização de humanos em experimentos (Cornwell, 2003; Gutman \& Berenbaum, 1998, Piper \& Swiebocka, 1996).

3) Os campos de extermínio de Sobibór, Belzec e Treblinka foram criados a partir da Operação Reinhardt (Arad, 1987; Roseman, 2003). O objetivo era acelerar a meta na eliminação dos inimigos do estado nazista a partir da criação de organizações especializadas no extermínio em massa. Após a definição da Solução Final para a questão judaica, plano de remover os judeus de todos os territórios da Alemanha nazista, os campos foram responsáveis por exterminar mais de um milhão e setecentas mil pessoas. Constituía-se em uma organização especializada na tarefa de exterminar dentro dos padrões produtivos industriais, inclusive com o objetivo de eliminar os corpos de suas vítimas (Arad, 1987; Roseman, 2003).

Essas três organizações compunham o chamado estado totalitário nazista (Arendt, 2013). Juntamente a elas, outras instituições do regime, como a polícia secreta Gestapo, a organização paramilitar Schutzstaffel (SS) e o exército alemão, a Wehrmacht, formavam uma rede cuja finalidade era executar as políticas raciais e de ocupação territorial na construção do império do Terceiro Reich (Evans, 2014; Snyder, 2012). Não há registro na história da humanidade de situação similar, quando tantas organizações se uniram sistematicamente para executar políticas eliminacionistas, nas quais o extermínio em massa tornou-se um fim em si mesmo.

4) A organização terrorista Al-Qaeda, que atua em forma de células independentes e colaborativas, está presente no Oriente Médio e possui simpatizantes em diversos países do mundo (Atwan, 2008; Burke, 2007; Gunaratna, 2002). A organização está baseada em princípios fundamentalistas islâmicos e já teve como líderes o saudita Osama Bin Laden e o egípcio Abu Muhammad Ayman al-Zawahiri. Surgiu como grupo paramilitar com o objetivo de expulsar do território afegão as tropas russas que invadiram o país. Sua atuação ganha capilaridade nas comunidades muçulmanas, onde exerce influência econômica, política e religiosa. Por isso, consegue recrutar voluntários para lutar na chamada Guerra Santa, cujo objetivo é expulsar os infiéis do território sob influência do islamismo (Atwan, 2008; Burke, 2007; Gunaratna, 2002). A Al-Qaeda foi responsável por diversos ataques terroristas, sendo o mais conhecido o atentado de 11 de setembro de 2001 às torres gêmeas do World Trade Center, em Nova Iorque, Estados Unidos.

5) O Estado Islâmico do Iraque e do Levante, mais conhecido atualmente como Estado Islâmico, está presente em diversos países do Oriente Médio e da Europa por meio de redes de células cooperativas (Napoleoni, 2014; Weiss \& Hassan, 2016). É uma organização terrorista que surgiu a partir do objetivo de estabelecer um califado em territórios de maioria sunita no Iraque (Napoleoni, 2014; Stern \& Berger, 2015; Weiss \& Hassan, 2016). Interpretam de forma fundamentalista as leis islâmicas e tentam impor seu modo de organização social, valores e crenças de forma violenta nos territórios sobre os quais passam a ter domínio. Adotam medidas violentas para impor a xaria código de leis islâmicas. A organização ganha poder a partir do seu estabelecimento como força paralela em países do Oriente Médio em que há guerras, como é o caso do Iraque e da Síria (Napoleoni, 2014; Stern \& Berger, 2015; Weiss \& Hassan, 2016). Tem como grande característica angariar adeptos e simpatizantes no mundo inteiro por se apresentar como uma organização do contra-poder dominante. Segundo Irshaid (2015) e Ascher-Schapiro (2015), é questionável a utilização do nome Estado Islâmico ao grupo fundamentalista analisado, pois ele efetivamente não se constitui como um estado no sentido tradicional no termo. Apesar da relevância da observação dos autores, optou-se por deixar a terminologia Estado Islâmico por ser a forma mais conhecida e utilizada no Brasil.

Adotar-se-á, neste trabalho, o ensaio como forma, segundo as concepções de Adorno (1986). Entende-se que os fatos históricos inerentes às organizações estudadas precisam ser compreendidos no seu tempo histórico dentro de uma perspectiva de totalidade em que se inserem e se inseriram. $\mathrm{O}$ 
ensaio permite o não cerceamento ou obliteração do ensaísta nas reflexões que apresenta. Permite também o uso de referências de diversas áreas do conhecimento sem cair no disciplinamento normativo das ciências particulares. Assim, este não é um trabalho historiográfico no sentido tradicional do termo, apesar de lançar mão de técnicas da historiografia e da análise histórica para compreender o fenômeno das organizações totalitárias. Ressalta-se que foi realizado levantamento sistemático, seleção criteriosa e análise detalhada das informações. Dentre os materiais analisados, destacam-se documentos, fotografias, documentários, áudios e bibliografias científicas.

McCann (2017) discute a relação entre gestão e guerra, mostrando que não há violência em escala no âmbito do conflito armado entre países, nações e grupos armados sem planejamento e organização. Estudar como a gestão e as formas organizativas estão presentes na constituição das relações intra e inter organizacionais e a sociedade é tentar compreender como as redes econômicas, políticas e sociais criam relações complexas e variadas no sistema de capital. Neste sentido, estudar as organizações totalitárias é tentar compreender como os fenômenos do autoritarismo, da violência, da intolerância, da obliteração da capacidade de refletir institui-se na forma mais radical dentro de uma organização. Mesmo que essa radicalidade não esteja presente no cotidiano das organizações tradicionais, de uma forma geral, ela está sempre latente. É importante lembrar também que muitas organizações que se relacionam direta e indiretamente com as organizações totalitárias são partícipes do processo de totalização, ou seja, adotando um relacionamento utilitário e funcional, aderem direta ou indiretamente às práticas autoritárias, violentas, intolerantes que degeneram o tecido social baseado no princípio da vida como bem primeiro e máximo que rege a vida em sociedade.

\section{Contexto Sócio-Histórico das Organizações Totalitárias}

O contexto sócio-histórico das organizações estudadas refere-se aos últimos cem anos e aos desdobramentos decorrentes da tendência totalizadora do sistema de capital. Esse sistema está baseado na produção em massa, na criação e concretização de um mercado, na mundialização do capital (Chesnais, 1996) e na sua incontrolabilidade (Mészáros, 2015). É responsável, também, por fortalecer a racionalidade instrumental a partir da consolidação de uma base técnico-científica. Apesar de estar fundamentado supostamente em pressupostos lógico-racionais, baseado no cálculo utilitário que organiza as dimensões da vida social, o sistema de capital não foi capaz de eliminar o que pode ser considerado uma das práticas mais irracionais no mundo: o extermínio em massa. Essa ideia está baseada em contribuições teóricas realizadas por pensadores como Adorno (2000), Horkheimer (2003) e Marcuse $(1975,1999)$ sobre a modernidade. A partir da análise das contribuições de obras clássicas como as de Marx (1974), Weber (1994) e Freud (1976, 1980, 1997), esses estudiosos procuraram compreender os fundamentos do processo civilizatório e seus desdobramentos sócio-históricos.

Apesar das diferenças epistemológicas, conceituais e mesmo metodológicas, sobretudo de Marcuse em relação a Adorno e Horkheimer (1985), esses pensadores analisaram como a barbárie se estabelece a partir do desenvolvimento das forças produtivas que se tornam dominantes e das racionalidades que se reproduzem historicamente. Para nenhum deles há uma relação de determinação histórica, apesar de reconhecerem o caráter negativo que o processo civilizatório adquire quando uma força produtiva e uma racionalidade consolidam-se como hegemônicas. Por conta disso, não deixam de criticar o sistema de capital, cujos fundamentos essenciais não se diferenciam das outras formas de produção históricas que também se baseavam na acumulação, exploração e na apropriação econômica, ideia que, de certa forma, pode ser encontrada na obra Economia e Sociedade, de Weber (1994).

Quando se analisa o contexto econômico que envolve as organizações totalitárias estudadas, no geral, percebe-se que o seu desenvolvimento está vinculado ao avanço das forças produtivas sob a lógica de uma racionalidade instrumental. Ou seja, de uma base técnica produtiva fundamentada na divisão técnica do trabalho, da produção baseada na especialização crescente do trabalho, da consolidação do conhecimento a partir da ciência como força motriz e da burocracia como produto do processo de racionalização, em que a autoridade racional-legal passa a ser dominante. Essas 
características fomentam e fortalecem um processo de reprodução sociometabólico no qual o capital torna-se a engrenagem central do processo civilizatório (Mészáros, 2015).

No entanto, é importante ressaltar que dentro da lógica da reprodução sociometabólica do capital, as organizações estudadas não podem ser enquadradas todas da mesma forma. O período histórico de sua existência, bem como as particularidades com que se estabelecem junto a grande burocracia dos estados nacionais, fazem com que tenham particularidades relevantes quando analisadas individualmente. Organizações como os Einsatzgruppen, o complexo de Auschwitz e os campos de extermínio da Operação Reinhard constituíam-se em organizações ligadas à estrutura formal e obedeciam às políticas oficiais de estado. Outros, como as organizações terroristas mencionadas mantinham vínculos de colaboração solidária com agentes estatais por meio de relações não oficiais e de natureza informal. Analisar-se-á algumas particularidades dessas organizações.

Quando se analisa o aparecimento do Einsatzgruppen, cujo objetivo era realizar execuções sumárias no leste europeu, percebe-se que estavam a serviço de uma política racial própria da Alemanha Nazista. Os seus princípios estavam baseados na eliminação de judeus, poloneses, ciganos, comunistas e todos aqueles que, de alguma forma, fossem contra os fundamentos fascistas que orientavam a política do governo alemão da época (Arad \& Krakowski, 1989; Rhodes, 2003). A ideia de uma nação constituída de pessoas de raça pura, a ariana, estava fundamentada em uma racionalidade baseada em mitos e ilusões típicos de uma Alemanha que, apesar possuir certo desenvolvimento das forças produtivas nos moldes dos princípios econômicos capitalistas, ainda estava presa a preconceitos típicos da Idade Média. Havia uma dissonância entre o desenvolvimento das forças produtivas, que requeriam maior integração com uma nova forma de orientar o desenvolvimento social, e a racionalidade instrumental, tão necessária para a expansão do sistema de capital. Os Einsatzgruppen agiam, em muitas situações, de forma semelhante às antigas organizações da Idade Média, cujo propósito era eliminar os infiéis, inimigos ou aqueles que não fossem considerados humanos.

A partir da Conferência de Wannsee, a política de assassinatos dos inimigos ganhou novos contornos e passou a realizar o extermínio em massa, baseado no modelo industrial de produção (Arad, 1987; Dwork \& Pelt, 2004; Roseman, 2003). A eficiência baseada na utilização da ciência como força produtiva foi capaz de dar novos contornos à barbárie. O complexo de Auschwitz é o melhor exemplo de como uma organização totalitária pode mudar de orientação ao longo de uma guerra. Sua função original era a de ser um campo de concentração, ou seja, de servir como local de aprisionamento e trabalho daqueles que eram considerados inimigos do estado nazista (Gutman \& Berenbaum, 1998; Piper \& Swiebocka, 1996). Com o tempo, ganhou novas funções para atender às necessidades de uma nação que passou a sofrer diretamente com o avanço do exército aliado. De campo de concentração de encarceramento, sua função passou à produção de bens e suprimentos para a própria guerra. Uma política de eliminação pelo trabalho passou a ser rotina. Milhares de pessoas morreram no ambiente de trabalho, seja por doenças, falta de higiene, fome ou por violência da guarda policial do campo (Gutman \& Berenbaum, 1998; Piper \& Swiebocka, 1996).

O funcionamento de Auschwitz estava amparado no desenvolvimento técnico-científico da época, sendo um importante local para experiências e inovações com vistas a assegurar a continuidade da barbárie. O campo abrigava importantes cientistas de diversas áreas (Cornwell, 2003), unidos pela crença da superioridade racial ariana e por uma política que distribuía benefícios para aqueles que aderissem ao ideal racial nazista. Integradas a eles, empresas eram parceiras do campo e do regime nazista para fornecer e desenvolver bens, serviços e recursos para a guerra. Era o caso da IBM, Volkswagen, Siemens, Bayer, Coca-Cola, Ford, entre outras (Dwork \& Pelt, 2004; Gutman \& Berenbaum, 1998; Mazower, 2013). O funcionamento de Auschwitz foi ampliado dentro de um processo de burocratização crescente do governo alemão, atendendo à lógica de um sistema de capital que passa a investir sempre mais recursos quando o processo de acumulação é maior.

Com o tempo e a entrada efetiva dos americanos na guerra e o reforço de outros países do ocidente, essa relação de colaboração foi se desfazendo. A escalada suicida do governo alemão por conta da sua política racial colocou em perigo os próprios princípios do sistema de capital (Dwork \& 
Pelt, 2004; Mazower, 2013). Primeiro, por causa da quebra do princípio do trabalho livre assalariado por meio do uso crescente de mão-de-obra escrava no sistema produtivo. Segundo, pela supressão do mercado consumidor, que ocorreu pela destruição do consumo livre a partir da ocupação territorial violenta e dominadora. Terceiro, pela própria degeneração do sistema de produção-circulaçãoconsumo devido ao extermínio sistemático de pessoas tanto no front de guerra como nos campos de concentração e extermínio. Quarto, pela epidemia da corrupção que se instalou no seio da sociedade, tanto no âmbito do governo como nas relações sociais de uma forma geral.

O sistema de capital está baseado na acumulação, apropriação e exploração do trabalho, que tende à incontrolabilidade. Por isso, é necessário que exista certa ordem interditora, no caso, a burocracia do estado moderno, que está baseada na autoridade racional-legal e atua como garantidora de certos princípios. A derrocada da irracionalidade do regime nazista foi a criação dos campos de extermínio, sobretudo os articulados na Operação Reinhard (Arad, 1987; Roseman, 2003). O funcionamento dos campos de extermínio de Sobibór, Belzec e Treblinka (Arad, 1987) é a prova de que o regime nazista adotou efetivamente uma política de autodestruição dos fundamentos necessários para a manutenção do sistema de capital tradicional, implicando a autodegeneração da própria racionalidade.

O mais contraditório em tudo isso é que a implementação da Solução Final para a Questão Judaica foi planejada e implementada a partir da primazia da racionalidade instrumental no plano prático das ações, para realizar o que se pode haver de mais irracional para a humanidade, que é o extermínio humano. Os campos de extermínio da Operação Reinhard associados a outros como os de Buchenwald, Bergen-Belsen, Chelmo, Dachau, Majdanek, Mauthausen, Sachsenhausen, por exemplo, integravam uma rede de organizações que adotaram os princípios da produção em massa, cuja eficiência produtiva era um objetivo em si mesmo e a adoção de aprimoramentos técnico-científicos era a lógica corrente do desenvolvimento de suas forças produtivas. Assim, sobre a jurisdição do estado totalitário nazista, os Einsatzgruppen, o campo de concentração de Auschwitz e os campos de extermínio da Operação Reinhard formaram uma rede de organizações totalitárias colaborativas para realizar o extermínio em massa de judeus, ciganos, inimigos políticos, deficientes físicos e mentais etc. a partir do que havia de mais desenvolvido na técnica da produção em larga escala. O que era, em início, ação isolada de extermínio de uma organização no complexo produtivo industrial alemão, passou a ser a própria lógica dominante que fundamentou a organização produtiva e econômica da Alemanha nazista, fato que pode ser comprovado a partir do fim do ano de 1941.

Em outro contexto temporal, mas sob a mesma lógica do sistema de capital, a Al-Qaeda formou-se como organização nos últimos trinta anos a partir de células colaborativas que obedecem aos preceitos da interpretação radical da xaria, base do fundamentalismo islâmico por ela adotada. Sua origem se dá no Afeganistão e seu objetivo inicial era combater e expulsar o exército russo que ocupava o país. Nesse período, a Al-Qaeda foi financiada e recebeu dos Estados Unidos doações de armas, equipamentos bélicos e treinamento (Atwan, 2008; Burke, 2007; Gunaratna, 2002). Todavia, após a instalação de bases militares dos americanos na Península Arábica, com o início da Guerra do Golfo, tornaram-se inimigos. A Al-Qaeda tem como princípio o controle territorial e a total preservação do que chama de terras sagradas do islã, ou seja, defende que nenhuma nação ocidental, cujos fundamentos religiosos, ideológicos e econômicos sejam distintos dos dela, possa ocupar ou estar presente em seus territórios (Burke, 2007; Gunaratna, 2002).

De certa forma, a Al-Qaeda é uma organização criada e financiada pelo ocidente. Sua forma de sistematização e atuação está atrelada às formas antigas existentes no Oriente Médio de comunidades nômades que vivem em processo de constante metamorfose social, obedecendo às leis e regras religiosas islâmicas. $\mathrm{O}$ desenvolvimento econômico baseado no mercado e na produção em série para consumo de massa não é um objetivo do grupo terrorista. Ao contrário, para eles, é preciso lutar contra essa forma de vida, pois esse tipo de lógica econômica leva os homens à degeneração dos princípios morais presentes nos fundamentos da religião islâmica. As interpretações mais radicais das leis islâmicas defendidas por integrantes da Al-Qaeda vêm dos escritos publicados por Sayyid Qutb, integrante da Irmandade Muçulmana (Atwan, 2008; Burke, 2007; Gunaratna, 2002). Entre suas principais ideias, há a necessidade de promover uma revolução islâmica de natureza armada com a 
finalidade de expulsar dos seus territórios todos os regimes, organizações e grupos não guiados pela lei islâmica. Outro preceito é o de criar o Califado Islâmico, com a união de todos os muçulmanos. Esses princípios podem ser considerados o grande thelos da Al-Qaeda e todos aqueles que colaborarem para sua realização são considerados colaboradores (Atwan, 2008; Burke, 2007; Gunaratna, 2002). Essa realidade demonstra que a organização não possui uma disposição tradicional como ocorre no mundo ocidental, ou seja, foge à lógica tradicional da racionalidade instrumental na sua criação, estruturação e funcionamento.

Apesar da sua recusa em incorporar os valores, as crenças e a lógica econômica ocidental como guias para a comunidade islâmica, a Al-Qaeda utiliza-se das tecnologias criadas no ocidente, assim como se beneficia de recursos financeiros provenientes de negócios realizados na economia tradicional. Acesso à internet para divulgar suas ações, armas usadas nos combates, meios de transportes, como carros, caminhões, aviões e equipamentos para espionagem, são alguns exemplos de tecnologia desenvolvida, produzida e comercializada na economia do ocidente. Muitas delas são compradas pelo grupo com recursos financeiros doados de forma clandestina por países que fazem negócio com as economias centrais dos países ocidentais e são utilizadas para a destruição (Burke, 2007).

O ápice da Al-Qaeda foi, sem dúvida, o ataque terrorista de 11 de setembro de 2001. Naquela ocasião, a organização passou a ser conhecida mundialmente e perseguida sistematicamente pelos Estados Unidos da América. Com a morte do seu principal líder, Osama bin Laden em 2011, quase dez anos após os ataques às Torres Gêmeas em Nova Iorque, o grupo se enfraqueceu. Com o aparecimento do Estado Islâmico, a Al-Qaeda perdeu notoriedade, pois grande parte do seu efetivo presente no Iraque passou a compor o novo grupo terrorista (Napoleoni, 2014; Stern \& Berger, 2015; Weiss \& Hassan, 2016).

O Estado Islâmico, por sua vez, também é uma organização baseada no fundamentalismo islâmico. É considerado ainda mais radical nas interpretações das leis islâmicas do que a própria $A l$ Qaeda. Formou-se a partir da reunião de várias organizações sunitas insurgentes, dentre elas a $\mathrm{Al}$ Qaeda do Iraque. Ao agregar diversos grupos de combatentes sunitas que lutavam contra a ocupação americana no Iraque, fundou uma organização que agrega grupos colaborativos com identidade própria, objetivos comuns, que professam a mesma fé religiosa e possuem a mesma forma de conceber o mundo. A lógica tribal existente no Iraque e em muitos países do Oriente Médio é um berço para o nascimento de grupos colaborativos que passam a atuar posteriormente como organização (Napoleoni, 2014; Stern \& Berger, 2015; Weiss \& Hassan, 2016). No entanto, diferentemente das organizações convencionais, os laços que unem esses grupos colaborativos não estão baseados na forma tradicional de distribuição de poder e do controle. Apesar da origem no Iraque, o Estado Islâmico ganhou força em sua atuação na guerra civil na Síria.

A Al-Qaeda e o Estado Islâmico resistem à incorporação da racionalidade técnica produtiva dominante da lógica do sistema de capital na estruturação da vida social. O sistema de capital é, em si mesmo, um dos alvos a ser combatido e por eles eliminado. Segundo a ideologia de base que sustenta a luta contra o ocidente, o capitalismo é um mal a ser extirpado, pois é contrário aos princípios de vida segundo as interpretações radicais das leis islâmicas. A lógica dessas organizações, portanto, é a de rompimento com a base produtiva e técnica que caracteriza a produção da existência material e espiritual da sociedade moderna ocidental. Isso não significa que, por obediência ou preceitos ideológicos, essas organizações não se utilizem dos aparatos técnicos desenvolvidos no sistema produtivo dominante. A internet, a produção audiovisual, as armas convencionais e não convencionais desenvolvidas com a ajuda da ciência, são recursos usados nos ataques terroristas com o objetivo de eliminar pessoas e símbolos do ocidente. A ideia é a da subversão da tecnologia e da base técnica moderna como prova de que o ocidente criou suas próprias condições de destruição. Está na base do pensamento fundamentalista islâmico o qual rege essas organizações que a destruição é intrínseca às escolhas profanas que o ocidente faz.

Outra característica relevante é que a vida, tão importante e essencial para o sistema de capital na relação de produção e consumo infinito, baseada na racionalidade instrumental, é, para os 
fundamentalistas islâmicos, algo que foge da sua finalidade teleológica. Guiar-se pelo princípio de uma vida que tem por objetivo a usura e o desfrute dos bens e serviços gerados pela modernidade é sem sentido e cheio de contradições para os radicais dessas organizações. Para eles, a vida é, em si mesma, o dedicar-se a um projeto maior, de natureza metafísica existencial, tal como a caracterizou, também, a sociedade ocidental na Idade Média sob uma visão teológica. O processo de racionalização que ocorreu no ocidente, baseado no ascetismo intramundano, segundo Weber (1994), ou do aparecimento do capital como ente organizador da vida social, segundo Marx (1974), não é algo que caracterizou os locais e comunidades que fomentaram o aparecimento do fundamentalismo islâmico. Isso implica afirmar que o sistema de capital, observado tardiamente no Oriente Médio, berço dessas organizações, entrou em conflito com a existência de uma racionalidade baseada em outros princípios estruturantes. Mesmo que a maioria dos integrantes da Al-Qaeda e do Estado Islâmico não seja formada pelo que podemos chamar de excluídos econômicos do sistema capitalista, o que se vê é a força do conflito ideológico que esses integrantes vivem na relação entre suas próprias crenças e aquelas presentes no mundo ocidental. A mera exclusão econômica não é garantia para a adesão de simpatizantes e militantes, sendo a inserção no sistema de racionalização muito mais relevante para o recrutamento dos radicais islâmicos. Por isso, é possível afirmar que essas organizações continuarão a ter adesões e simpatizantes do mundo inteiro, porque o sistema de capital e o processo de racionalização instrumental são geradores de contradições que mobilizam a faceta irracional presente em qualquer sociedade.

\section{Modus operandi: do assassinato ao extermínio sistemático}

A proposta, aqui, é discutir o modus operandi dos assassinatos praticados pelas organizações estudadas. Alguns elementos influenciam diretamente a maneira como elas planejam, organizam e implementam as formas de matança. Dentre esses elementos, destacam-se: as técnicas utilizadas nos atos dos extermínios, as ações de violência praticadas e a extensão da destruição ocasionada. A combinação desses elementos define, de forma geral, as características dos assassinatos perpetrados por essas organizações. Obviamente, não se trata aqui de definir uma tipologia ou uma forma de classificação quanto às práticas dos homicídios, mesmo porque seria irrelevante do ponto de vista ético e moral. A ideia é assimilar como esses elementos estabelecem uma relação de interação entre si, possibilitando compreender o movimento da organização de maneira sistêmica e os possíveis desdobramentos quanto à forma de poder instituído dentro da sociedade.

$\mathrm{O}$ assassinato como finalidade per se é um fato comum entre as organizações totalitárias. Entretanto, as diferenças variam conforme o nível de acesso da organização aos recursos econômicos, materiais e tecnológicos; o grau de dependência e autonomia em relação à burocracia central do estado; o modo de envolvimento com a comunidade na qual está inserida e a forma como os assassinatos são praticados.

O que é comum a todas as organizações são os atos de planejar, organizar e implementar os assassinatos. Enquanto os Einsatzgruppen realizavam assassinatos coletivos organizados com a ajuda da comunidade local, o campo de concentração e extermínio de Auschwitz chegou a exterminar de forma sistemática, sob a lógica de produção industrial, seis mil pessoas por dia. O fato é que os atos de planejar, organizar e implementar comprovavam uma sistematização efetiva dos assassinatos, independentemente do número de vítimas. A diferença quantitativa de pessoas mortas estava diretamente associada ao envolvimento, direto ou indireto, da organização com os estados nacionais, com a base técnica e com as condições tecnológicas existentes e utilizadas no processo. No entanto, todas as organizações revelam-se igualmente bárbaras, pois, do ponto de vista qualitativo, todas as vidas são, na mesma medida, importantes para a humanidade.

Os Einsatzgruppen atuaram no leste europeu e foram responsáveis por eliminar mais de um milhão e meio de judeus, ciganos, deficientes, políticos da inteligência polonesa, soviéticos e todos aqueles considerados inimigos do estado nazista entre os anos de 1941 e 1943, após a invasão do território russo. Eles vinham, geralmente, acompanhando o exército alemão e, após este invadir e ocupar o território inimigo, eram os responsáveis pelos assassinatos, principalmente de civis (Arad \& 
Krakowski, 1989; Rhodes, 2003). Formavam quatro grandes unidades, divididos em diversos comandos. Registros fotográficos, depoimentos e alguns documentos resgatados demonstram que havia um padrão para a matança. Entre dois e cinco perpetradores atiravam nas costas das vítimas que eram enfileiradas nas bordas ou dentro de valas, após se despirem e deixarem todos os seus pertences para trás que, invariavelmente, eram roubados pelos seus algozes (Arad \& Krakowski, 1989; Rhodes, 2003). Primeiro, eram assassinados os homens, depois mulheres e crianças. Esse procedimento evitava que os homens se rebelassem caso presenciassem primeiramente o assassinato de suas mulheres e crianças (Arad \& Krakowski, 1989; Rhodes, 2003). A vala cheia era coberta com terra, uma camada de cal e mais uma camada de terra. Quem geralmente fazia o fechamento das valas eram colaboradores das comunidades locais ou mesmo futuras vítimas. Muitos eram enterrados vivos, pois nem sempre os tiros causavam a morte imediata. $\mathrm{O}$ perfil dos executores era comumente o de funcionários do estado nazista: geralmente homens hábeis, inteligentes, muitos com doutorado e de boa conduta social e convicções alinhadas com os preceitos raciais da política eliminacionista. Recebiam ajuda da comunidade local, de tendência antissemita e anticomunista. No geral, os comandos eram compostos por $60 \%$ (sessenta por cento) de alemães e $40 \%$ (quarenta por cento) de colaboradores locais. Com o tempo, esse procedimento de matança foi causando problemas porque os ofensores passaram a manifestar distúrbios psicológicos. Submetidos diariamente à tarefa de exterminar, passaram a vivenciar a perda do sentido do seu trabalho. Realizavam tarefas desumanas, o que provocava a dessensibilização e acarretava desobediência às ordens superiores.

Os Einsatzgruppen foram o primeiro passo para a execução da Solução Final (Arad \& Krakowski, 1989; Rhodes, 2003; Roseman, 2003), antecedendo os campos de extermínio. Foram responsáveis por implementar, no verão de 1941, um novo método de aniquilação, desenvolvendo tecnologias mais sofisticadas, como caminhões que emitiam monóxido de carbono e matavam as vítimas por asfixia. Testaram, ainda, o uso de explosivos, o que foi considerado ineficiente porque mutilava os corpos e o recolhimento das partes exigia uma logística um tanto quanto difícil. Os Einsatzgruppen foram responsáveis por eliminar comunidades inteiras, deixando para trás cidades completamente vazias. Com o tempo, esse método de extermínio mostrou-se limitado e pouco eficiente para os propósitos nazistas. Por conta disso, passaram a investir em outras formas de organização para realizar as execuções (Arad \& Krakowski, 1989; Rhodes, 2003). O campo de Chelmo foi o que serviu de modelo à grande maioria dos campos que surgiram posteriormente (Dwork \& Pelt, 2004), entre eles o de Auschwitz.

O complexo de Auschwitz foi responsável por exterminar mais de dois milhões e meio pessoas de diversas formas. Muitas morreram de fome, outras por doenças decorrentes das condições sanitárias deploráveis em que viviam e outras, ainda, por torturas e maus tratos praticados pelos guardas alemães contra os prisioneiros no campo de concentração de Auschwitz I (Allen, 2005; Gutman \& Berenbaum, 1998; Piper \& Swiebocka, 1996). Em Auschwitz II-Birkenau, os assassinatos ganharam proporções descomunais através do uso, nas câmaras de gás, do veneno Zyklon-B. Foram utilizados crematórios para eliminar os corpos das vítimas. Salienta-se o fato de que o sistema de produção da morte ganhou características industriais e, como toda linha de produção eficiente, estava balizado por processos que envolviam a avaliação da eficiência do sistema e o controle de qualidade do serviço executado (Allen, 2005; Gutman \& Berenbaum, 1998; Piper \& Swiebocka, 1996). A racionalidade instrumental adquiria a sua forma moderna mais eficiente: uma burocracia organizacional na qual as condições de produção possuíam primazia sobre a própria humanidade. Em Auschwitz II-Monovitz, a morte acontecia por exaustão e estafa no trabalho. O campo era um complexo industrial que se utilizava de mão-de-obra escrava. A máxima presente no portão de entrada do complexo de Auschwitz, arbeit macht frei, ou seja, o trabalho liberta, era levada a cabo, pois a grande maioria dos trabalhadores escravos acabavam morrendo por motivos decorrentes do trabalho exaustivo somados às más condições de vida (Allen, 2005; Gutman \& Berenbaum, 1998; Piper \& Swiebocka, 1996).

Os campos de extermínio da Operação Reinhard - Belzec, Sobibór, Treblinka - foram construídos com a tarefa especializada de exterminar. Estima-se que, nos três campos, aproximadamente um milhão e setecentas mil pessoas foram mortas (Arad, 1987). Assim como em Auschwitz, as vítimas chegavam aos campos por meio de linhas férreas construídas especificamente 
com essa finalidade. Estavam localizados geralmente em áreas isoladas, com o intuito de ocultar sua existência. $\mathrm{O}$ desembarque das vítimas era feito de forma a não causar pânico. Era imprescindível que as pessoas não suspeitassem que seriam exterminadas, para evitar rebeliões e tumulto (Arad, 1987; Dwork \& Pelt, 2004). Geralmente, as vítimas eram divididas entre homens, mulheres e crianças, tendo aqueles prioridade no extermínio. Essa ação garantia maior controle no processo: se mulheres e crianças fossem exterminadas primeiramente e tal manobra fosse percebida pelos homens, isso poderia desencadear reações de resistência violentas (Arad, 1987; Dwork \& Pelt, 2004).

As vítimas eram despidas sob o pretexto de que iriam tomar banho e seriam posteriormente levadas aos locais onde passariam a viver. Os objetos delas retirados eram apropriados pelo estado nazista ou, em muitas ocasiões, roubados por guardas de segurança. Após se despirem, eram levadas às câmaras e, ao invés de serem banhadas por água, as vítimas eram surpreendidas e inalavam monóxido de carbono, o que causava morte por asfixia. Em alguns casos também, foi usado o veneno Zyklon-B. Após o assassinato, os sonderkommandos, grupos organizados e compostos por prisioneiros recém chegados ao campo, tinham as tarefas de levar os corpos aos crematórios, enterrá-los quando esse era o procedimentos a ser adotado, fazer a limpeza das câmaras de gás e outros serviços que os funcionários alemães não gostavam de realizar. A sobrevida dos integrantes dos sonderkommandos era de poucos dias, pois eles mesmos eram executados posteriormente e substituídos por novos membros.

As organizações totalitárias criadas e desenvolvidas pelo estado nazista fomentaram assassinatos em massa de dimensões incomparáveis até hoje. A política eliminacionista amparada por uma pseudociência nazista que sustentava a ideologia da superioridade racial ariana sobre as demais foi responsável por uma guerra de proporções globais que exterminou seis milhões de judeus e outros milhões de soviéticos, ciganos, deficientes físicos e mentais e inimigos do estado nazista.

Em relação à Al-Qaeda, não há forma preferida ou padrão na realização das execuções. Como a organização está imersa no conflito permanente com as forças de segurança de vários estados nacionais, as execuções obedecem à lógica do momento oportuno de sua realização. Sem o amparo estatal de uma nação ou país, ao menos direta e formalmente, as estratégias de ação estão baseadas em formas organizadas e planejadas, subordinadas às oportunidades que ocorrem, em verdade, em decorrência de brechas na segurança e na falta de controle dos órgãos de segurança e controle social dos países e nações (Atwan, 2008; Burke, 2007; Gunaratna, 2002). Por conta disso, e pela crença na vida ideal que ocorre no pós-morte de acordo com o merecimento a partir das ações de devotamento e doação total na vida terrena, o ato de suicídio é a forma mais comum que leva à execução dos inimigos. Apesar de ser condenado pelos valores e crenças da religião islâmica, o martírio em favor da criação do reino islâmico na terra é tido como um valor superior. Aliás, todos os atos são justificados perante a vontade de Alá, desde que sejam voltados à instituição do califado e à destruição dos infiéis aos princípios islâmicos.

Assim, os atos suicidas praticados pelos mártires possuem um valor em si mesmo. Os campos de treinamento da Al-Qaeda são organizados para desenvolver qualidades físicas, psicológicas e mentais que possibilitem o cumprimento dessas missões. O objetivo maior dos suicidas é a devoção total e integral, que só se efetiva com a concretização do ato terrorista. Percebe-se que a violência consiste não somente no assassinato de outras pessoas, mas no ato de destruir-se a si mesmo como prova de fé e merecimento pelo sacrifício. As ações terroristas da Al-Qaeda focam no sucesso da missão e qualquer outro ato de violência decorrente só adquire valor caso o sucesso seja alcançado (Atwan, 2008; Burke, 2007; Gunaratna, 2002).

As formas das missões suicidas poderiam mudar conforme as possibilidades contextuais. A mais comum era a do homem bomba, que consistia em amarrar em seu próprio corpo explosivos e, no momento oportuno, detoná-los diante da multidão considerada infiel ou inimiga do islã. Vários foram os atentados terroristas assim perpetrados. Essa forma de ataque não era a única, mas passou a ser reproduzida por conta dos resultados obtidos. O sucesso advinha da forma inesperada como ocorria: quem imagina ser morto por alguém que pretende assassinar o outro se autodestruindo no mesmo ato? Para os valores ocidentais, o suicídio é algo indigno que vai contra os princípios morais e legais vigentes. Essa estratégia de extermínio possibilita que os assassinos estejam infiltrados não só em 
países onde a Al-Qaeda tenha campos de treinamento, mas em praticamente todos os locais onde a circulação livre de pessoas aconteça. Por conta disso, os atentados podem ocorrer não só em países do Oriente Médio, mas também em noções europeias, africanas, asiáticas, americanas, ou seja, em quase a totalidade do mundo.

O ato terrorista de 11 de setembro de 2001, que culminou na derrubada das torres gêmeas do World Trade Center, em Nova Iorque, por aviões comerciais, mudou o padrão vigente dos atos terroristas. Com esse feito, o número de vítimas dos atos suicidas ganhou novas dimensões. Estima-se que mais de quatro mil pessoas tenham morrido por estarem nas torres e nos aviões que foram usados para com elas colidir. Além da representação simbólica em derrubar as torres, consideradas símbolos da grandiosidade do sistema financeiro capitalista, o uso dos aviões como armas demonstrava o poder de destruição implícito nas tecnologias desenvolvidas e criadas a partir de uma base técnica orientada para a exploração econômica. Outro fator que viabilizou a implementação do terror é que, pela primeira vez na história, um evento terrorista foi filmado e presenciado quase que simultaneamente ao seu acontecimento por espectadores globais através da mídia televisiva e da internet.

Assim como a Al-Qaeda, o Estado Islâmico é uma organização não convencional, baseada em células de combates colaborativas e motivadas pela Guerra Santa e pela criação de um Califado islâmico. Mais radicais do que os integrantes da Al-Qaeda, a proposta do Estado Islâmico é a eliminação de todos que se contrapõem a seus princípios radicais religiosos. Perseguem também muçulmanos considerados infiéis e todos aqueles que se declaram politeístas ou de outras religiões. Utilizam martírios, combates militares, armas químicas e não convencionais em suas práticas de extermínio. Fazem da violência extrema um princípio civilizatório per se. Em virtude disso, executam suas vítimas por meio de homens-bomba, decapitações, atos incendiários contra pessoas vivas, fuzilamentos e esfaqueamentos. Filmam e divulgam os assassinatos na internet, com a intenção de infligir medo naqueles que consideram inimigos e, ao mesmo tempo, demonstrar força e coragem. Representam a versão moderna do salafismo radical e consideram o estado de guerra permanente essencial para o sucesso da Jihad internacional (Napoleoni, 2014; Stern \& Berger, 2015; Weiss \& Hassan, 2016).

O Estado Islâmico vive e se reproduz em um contexto complexo de conflitos no Oriente Médio. Fortaleceu-se com a presença norte americana no Iraque, tornando-se uma opção de resistência à sua ocupação. Na Síria, luta contra o governo do ditador Bashar al-Assad, ocupando e controlando parte da nação. É financiado por recursos oriundos da venda clandestina de petróleo explorado nos territórios ocupados. Ganha apoio e adeptos nas tribos e comunidades locais por levarem comida e ofertarem proteção. Cobram, em contrapartida, fidelidade religiosa e obediência às suas regras. Promovem ataques terroristas e conflitos armados em diversos países do mundo. Consideram os países do ocidente inimigos permanentes. Com seus atos de violência e sua ideologia radical, passam a ter admiradores, seguidores e colaboradores no mundo inteiro. Apresentam-se como os responsáveis pela maioria dos atos terroristas que ocorrem na Europa. Seu modus operandi incorpora o princípio da ação por oportunidade. Os treinamentos são iniciados desde cedo pelas crianças, muitas delas sequestradas de seus inimigos e convertidas ao radicalismo islâmico. São responsáveis, também, por sequestros de meninas e mulheres que se tornam escravas sexuais (Napoleoni, 2014; Stern \& Berger, 2015; Weiss \& Hassan, 2016). A morte é adorada e, ao contrário dos valores da civilização ocidental, é uma finalidade estruturante do seu processo civilizatório (Napoleoni, 2014; Stern \& Berger, 2015; Weiss \& Hassan, 2016).

Em suma, todas as organizações procuram certa eficiência, ou seja, pautam-se na racionalidade instrumental para conseguir obter os melhores resultados possíveis. Essa eficiência se dá pelas vantagens econômicas decorrentes das ações de cada uma, no seu contexto, a partir de suas práticas de extermínio. Mesmo as organizações Al-Qaeda e Estado Islâmico, com sua ideologia contrária aos ideais ocidentais, acabam sendo impregnadas, de certa forma, pela lógica da racionalidade instrumental. Ao se utilizarem dos artefatos tecnológicos e recursos financeiros provenientes do ocidente, incorporam sutilmente os entes estruturantes do processo de racionalização existente como forma dominante do mundo ocidental. 
A análise do contexto sócio-histórico e do modus operandi das organizações totalitárias mostra que elas promovem o estabelecimento do terror social, da aniquilação do humano e da instituição do mal. Essa tríade é responsável pela sobreposição da barbárie, baseada no extermínio, em detrimento àquilo que lhe é diametralmente oposto: a vida como valor essencial à humanidade. $\mathrm{O}$ tema será desenvolvido a seguir.

\section{Os Fundamentos das Organizações Totalitárias: O Terror Social, a Aniquilação do Humano e a Instituição do Mal}

O assassinato é a prática da eliminação do outro, de forma a tirar a vida e impedir a continuidade da existência da vítima. Os assassinatos são comuns na história da humanidade e impedilos por completo parece ser algo impossível. Mas as práticas de assassinatos, perpetrados por qualquer motivo, podem ganhar variações quantitativas conforme o modo de organização da sociedade de produção, da sua existência material e espiritual.

Sempre ocorreram extermínios coletivos na história da humanidade. Entretanto, sob a lógica do sistema de capital e da racionalidade instrumental, os assassinatos ganharam números em escala industrial - como no caso das organizações totalitárias do estado nazista - e contornos que combinam antigas formas medievais de execução com a utilização de tecnologias modernas para ampliar o número de mortos, situação experimentada pelas organizações terroristas aqui estudadas. Apesar disso, é possível afirmar que essas organizações estão fundamentadas dentro de uma mesma lógica no contexto do sistema de capital e na consolidação da racionalidade instrumental.

Os fundamentos de uma organização são o que alicerçam sua existência. Portanto, estão intimamente ligados à sua finalidade e, para compreendê-los, é preciso conhecer seu modus operandi. É necessário ir além da mera aparência daquilo que a organização faz. É preciso entender o que o particular, ou suas práticas e ações específicas, tem em relação ao contexto sócio-histórico que a envolve. Ao analisar as organizações estudadas, apesar de suas particularidades, percebe-se que são três os elementos em comum que constituem seus fundamentos: o terror social, a aniquilação do humano e a instituição do mal.

Com sua origem na Revolução Francesa, no período que ficou conhecido como o Reino do Terror (1793-1794), o terror social é caracterizado pela presença do medo constante da violência extrema, do assassinato e da brutalidade. As organizações totalitárias têm como fundamento estabelecer o terror no âmago da vida social daqueles que consideram inimigos. O terror torna-se um meio de socialização e de estruturação das relações. Destrói os vínculos afetivos positivos entre os indivíduos e cria a degeneração dos valores morais, como a solidariedade, a compaixão e a amizade. Poucos são os que resistem a essa degeneração. Nesse contexto, vítimas, perpetradores, cooperadores e colaboradores diretos e indiretos passam a organizar sua vida dentro de relações pragmáticas e utilitárias.

O terror social tem sua morada no princípio da destruição humana. Provoca a reificação do sujeito na história, desenvolve a incapacidade de reflexão sobre as contradições inerentes à sociedade e desenvolve a derrota do pensamento de protesto (Marcuse, 1976). Potencializa a racionalidade instrumental na direção da destruição do homem pelo homem, amparada pelo desenvolvimento científico e tecnológico aplicado à destruição em massa. Inibe ações de solidariedade voltadas para a preservação da vida e aquelas de natureza altruísta. Provoca a incapacidade de pensamento e reflexão por conta própria, segundo Hannah Arendt (1999). Converte o sujeito em bárbaro. Rareia os atos que vão contra a lógica instrumental. Transforma a consciência em articuladora de cálculos utilitários para a obtenção de fins, tornando os sujeitos meros cumpridores de ordens burocráticas. No regime de terror social, atos de violência extremas são frequentes. Torturas, estupros, esquartejamentos, atear fogo em pessoas, agressões físicas, psicológicas e morais fazem parte do cotidiano. O terror social é 
desencadeador do retorno à horda, fomentador do darwinismo social e da estruturação de uma socialização voltada para a destruição da subjetividade e, com o tempo, da própria razão.

Outro fundamento das organizações totalitárias é a aniquilação do humano. Ela se baseia na indiferença em relação à vida. Provoca a perda total da individualidade em virtude do controle extremo que a organização passa a exercer sobre os sujeitos. Provoca a perda da concepção universal de igualdade entre os homens. Por isso, cria o imaginário de que as diferenças entre raças, credos e ideologias, sejam, em si mesmas, suficientes para definir o humano e o não-humano. Fomenta a ideia de que existem os merecedores e os não merecedores da sua própria existência. A perda do humano transforma a dor, a angústia e o sofrimento em valores inferiores que só os fracos valorizam. Na aniquilação do humano, os indivíduos, frequentemente, são induzidos a viver um cotidiano com a presença permanente da morte.

A aniquilação do humano é sectária da morte, mas não daquela morte que vem como processo natural do devir de cada homem, em que o singular se concretiza na particularidade do morrer que cada um vivencia. A aniquilação é discípula da perda do singular que ocorre quando a morte é realizada de forma sistemática, produzida em série, como ocorre com produtos fabricados em linhas de produção, que não possuem nenhuma identidade particular se comparados a qualquer outro produzido no mesmo lugar ou em local distinto que empregue a lógica da impessoalidade, da padronização e da profissionalização. A aniquilação do humano é acompanhada da destruição de provas (instalações, documentos, silêncio às falas dos envolvidos etc.) como forma de obliterar a própria história da vítima no seu contexto social. Diferente da vida animal, em que a história de um é a história de todos, uma das características propriamente humanas é a garantia aos indivíduos da possibilidade de conhecimento da sua trajetória pessoal, da sua individualidade e da experimentação da particularidade no universal da humanidade.

O terceiro fundamento das organizações totalitárias é a instituição do mal. Na filosofia, essa questão já foi analisada por Kant (1992), Santo Agostinho (1995), Leibniz (2000) e Arendt (1999). Não é o objetivo, aqui, discutir conceitualmente os elementos que levaram cada um desses filósofos a definir o conceito. Parte-se do pressuposto que o mal, na sua forma física, moral ou metafísica, é caracterizado pela prática da eliminação do outro, destruindo não só sua vida física, mas sua memória, sua história e a possibilidade de existência futura por meio da aniquilação de sua cultura e de seus sucessores. O mal não seria, portanto, apenas a ausência do bem, mas a tendência à destruição de todas as dimensões da vida humana. Dessa forma, trata-se aqui de fundamentar o mal de forma objetiva a partir da ideia de Wolff (2004) sobre a barbárie. Se o bárbaro é todo aquele que propõe a eliminação do outro, o mal nada mais é do que a efetivação da eliminação do outro na sua totalidade, inclusive na possibilidade da existência do devir. O mal se alimenta do ódio, intrínseco à condição humana. Mas se efetiva somente no coletivo. Ou seja, não é um atributo individual, mas uma instituição coletiva. Quando esse ódio é direcionado a uma pessoa ou a um grupo delas com determinadas características e se torna compartilhado, tem-se a instituição do mal. As organizações totalitárias visam não somente ao assassinato de pessoas, mas à aniquilação do humano, à extinção total de possibilidades do devir de um coletivo, de uma comunidade, de uma cultura. Esse fato pode ser comprovado por atos planejados em exterminar crianças ou submetê-las à violência extrema com a finalidade de fazê-las negar sua origem e cultura, como são feitos pelas organizações terroristas aqui estudadas.

Quando o mal institui-se e torna-se dominante nas relações sociais, todos que estão a ele ligados passam a ser vítimas, inclusive os perpetradores que não mais estão seguros quanto à possibilidade de evitar sua própria aniquilação em virtude da contrarreação natural às suas práticas de extermínio e violência. A reprodução do mal está alinhavada no processo sociometabólico, inerente ao sistema de capital, que, além de estruturar a lógica de produção e consumo, é responsável por instituir a racionalidade instrumental em todos os âmbitos da vida social.

Um dos aprendizados deixados por esses acontecimentos históricos é que a existência da razão formal, por meio da racionalidade instrumental presente na consolidação de um sistema burocrático, não é suficiente para garantir o princípio da humanidade. Existe algo de irracional que é perene na história da humanidade e a barbárie como a concretização da irracionalidade é um desejo permanente 
nos homens. Nem mesmo um sistema econômico pode eliminar a irracionalidade que está na constituição do ser. O máximo que se consegue é tentar conter o devir da destruição total ou frear sua voracidade nos momentos em que a violência extrema está próxima de se transformar na aniquilação do humano. Nessa esteira, nem mesmo o sistema de capital é capaz de conter a barbárie. Ao contrário: torna-se responsável ou por dar a ela proporções industriais, quando as organizações totalitárias estão sob a lógica do estado totalitário, ou mesmo por fomentá-la, quando essas mesmas organizações se constituem para combater a tendência totalizadora e a racionalidade instrumental, próprias desse sistema.

Apesar do cenário aterrorizador, a história prova que, em meio às ações das organizações totalitárias da época do regime nazista, pessoas e coletivos agiram para evitar o estabelecimento do terror social, a aniquilação do humano e a instituição do mal. Histórias como a da enfermeira Irena Sendler, que atuou no Gueto de Varsóvia, na Polônia, e ajudou mais de duas mil e quinhentas crianças judias a se salvar do extermínio; a de Oskar Schindler, que, apesar de ser alemão, conseguiu empregar vários judeus nas suas fábricas impedindo-os de serem levados aos campos de extermínio; a do britânico Nicholas Winton, que conseguiu evitar que mais de setecentas crianças fossem enviadas da Checoslováquia para os campos de extermínio; a da brasileira Aracy de Carvalho Guimarães Rosa, que burlou a burocracia e emitiu diversos vistos para que judeus viessem morar no Brasil e não fossem mortos, são exemplos de que é possível se fazer o certo e impedir a barbárie (Grunwald-Spier, 2011). $\mathrm{O}$ mesmo acontece agora, quando milhares de pessoas estão agindo para ajudar pessoas contra as atrocidades cometidas pelo Estado Islâmico. No fim, esses indivíduos e coletivos que ajudaram a salvar milhares de pessoas atendem ao imperativo formulado por Jans Jonas a partir da proposta por Kant:

'Aja de modo a que os efeitos da tua ação sejam compatíveis com a permanência de uma autêntica vida humana sobre a Terra'; ou, expresso negativamente: 'Aja de modo a que os efeitos da tua ação não sejam destrutivos para a possibilidade futura de uma tal vida'; ou, simplesmente: 'não ponha em perigo as condições necessárias para a conservação indefinida da humanidade sobre a Terra'; ou, em um uso novamente positivo: 'Inclua na tua escolha presente a futura integridade do homem como um dos objetos do teu querer' (Jonas, 2006, pp. 47-48).

Como dica para pesquisas futuras, é interessante analisar como o terror social, a aniquilação do humano e a instituição do mal se apresentam, ou não, em níveis distintos nas organizações convencionais e tradicionais. A partir das contribuições dos diversos autores mencionados neste artigo, é possível, ainda, ter elementos teóricos para estabelecer um diálogo e compreender como as organizações totalitárias estão relacionadas simbioticamente com o funcionamento do sistema de capital.

\section{Agradecimento}

Agradeço à Fundação Araucária, órgão de fomento à pesquisa da Secretaria de Estado da Ciência, Tecnologia e Ensino Superior (SETI-PR) do Estado do Paraná, pelo apoio financeiro à pesquisa realizada.

\section{Referências}

Adorno, T. W. (1986). O ensaio como forma. In G. Cohn (Org.), Sociologia: Adorno (pp. 167-187). São Paulo: Ática.

Adorno, T. W. (2000). Educação e emancipação. Rio de Janeiro: Paz e Terra.

Adorno, T. W., \& Horkheimer, M. (1985). Dialética do esclarecimento. Rio de Janeiro: Zahar. 
Agostinho, S. (1995). O livre-arbítrio. São Paulo: Paulus.

Allen, M. T. (2005). The business of genocide: The SS, slave labor, and the concentration camps. Chapel Hill, NC: University of North Carolina Press.

Arad, Y. (1987). Belzec, Sobibor, Treblinka: The operation Reinhard death camps. Bloomington: Indiana University Press.

Arad, Y., \& Krakowski, S. (1989). The Einsatzgruppen reports: Selections from the dispatches of the Nazi Death Squads' campaign against the jews July 1941 - January 1943. New York, NY: Holocaust Library.

Arendt, H. (1999). Eichmann em Jerusalém: Um relato sobre a banalidade do mal. São Paulo: Companhia das Letras.

Arendt, H. (2013). Origens do totalitarismo: Antissemitismo, imperialismo, totalitarismo. São Paulo: Companhia das Letras.

Ascher-Schapiro, A. (2015). Call It ISIS, ISIL, or Daesh - the Islamic State still wants to kill you. Retrieved from https://news.vice.com/en_us/article/d39dvq/call-it-isis-isil-or-daesh-the-islamicstate-still-wants-to-kill-you

Atwan, A. B. (2008). A história secreta da Al-Qaeda. São Paulo: Larousse do Brasil.

Benjamin, W. (2015). O capitalismo como religião. São Paulo: Boitempo Editorial.

Burke, J. (2007). Al-Qaeda: A verdadeira história do radicalismo islâmico. Rio de Janeiro: Zahar.

Cornwell, J. (2003). Os cientistas de Hitler: Ciência, guerra e o pacto com o demônio. Rio de Janeiro: Imago.

Charny, I. W. (1982). How can we commit the unthinkable? Genocide: The human cancer. Boulder, Colo: Westview Press.

Charny, I. W. (1998). Anatomia do genocídio: Uma psicologia da agressão humana. Rio de Janeiro: Rosa dos Tempos.

Chesnais, F. (1996). A mundialização do capital. São Paulo: Xamã.

Dwork, D., \& Pelt, R. J. van (2004). Holocausto: Uma história. Rio de Janeiro: Imago.

Evans, R. J. (2014). A chegada do Terceiro Reich. São Paulo: Editora Planeta do Brasil.

Freud, S. (1976). Edição standard brasileira das obras psicológicas completas de Sigmund Freudvolume XIII: Totem e tabu e outros trabalhos (1913 1914). Rio de Janeiro: Imago.

Freud, S. (1980). Edição standard brasileira das obras psicológicas completas de Sigmund Freudvolume XXIII: Moisés e o monoteísmo, esboço de psicanálise e outros trabalhos (1913 1939). Rio de Janeiro: Imago.

Freud, S. (1997). Edição standard brasileira das obras psicológicas completas de Sigmund Freudvolume XXI: $O$ futuro de uma ilusão, o mal-estar na civilização e outros trabalhos (1927 1931). Rio de Janeiro: Imago.

Gellately, R., \& Kiernan, B. (2003). The specter of genocide: Mass murder in historical perspective. New York, NY: Cambridge University Press.

Goffman, E. (2010). Manicômios, prisões e conventos (8a ed.). São Paulo: Perspectiva. 
Grunwald-Spier, A. (2011). Os outros Schindlers. São Paulo: Cultrix.

Gunaratna, R. (2002). Inside Al-Qaeda: Global network of terror. New York, NY: Columbia University Press.

Gutman, Y., \& Berenbaum, M. (1998). Anatomy of the Auschwitz death camp. Indiana: Indiana University Press.

Henry, M. (2012). A barbárie. São Paulo: É Realizações Editora.

Horkheimer, M. (2003). Eclipse da razão. São Paulo: Centauro.

Irshaid, F. (2015 December 2). Isis, Isil, IS or Daesh? One group, many names. Retrieved from http://www.bbc.com/news/world-middle-east-27994277

Jonas, H. (2006). O princípio responsabilidade: Ensaio de uma ética para a civilização tecnológica (pp. 47-48). Rio de Janeiro: Contraponto.

Kant, I. (1992). A religião nos limites da simples razão. São Paulo: Escala.

Leibniz, G. W. (2000). Theodicy: Essays on the goodness of God, the freedom of man and the origin of evil. New York, NY: Wipf and Stock Publishers.

McCann, L. (2017). 'Killing is our business and business is good': The evoluti on of 'war managerialism' from body counts to counterinsurgency. Organization, 24(4), 491-515. https://doi.org/10.1177/1350508417693852

Marcuse, H. (1975). Eros e civilização: Uma crítica filosófica ao pensamento de Freud. Rio de Janeiro: Zahar.

Marcuse, H. (1976). A ideologia da sociedade industrial. Rio de Janeiro: Zahar Editores

Marcuse, H. (1999). Tecnologia, guerra e fascismo (D. Kellner, ed.). São Paulo: Editora da UNESP.

Marx, K. (1974). O capital: Crítica da economia política. Livros I, II e III. Rio de Janeiro: Civilização Brasileira.

Mattéi, J.-F. (2002). A barbárie interior: Ensaio sobre o i-mundo moderno. São Paulo: Editora da UNESP.

Mazower, M. (2013). O império de Hitler: A Europa sob o domínio nazista. São Paulo: Companhia das Letras.

Mészáros, I. (2015). Para além do capital: Arumo a uma teoria da transição. São Paulo: Boitempo Editorial.

Napoleoni, L. (2014). The islamist phoenix: The Islamic State and the redrawing of the middle east. New York, NY: Seven Stories Press.

Novaes, A. (Org.). (2004). Civilização e barbárie. São Paulo: Companhia das Letras.

Piper, F., \& Swiebocka, T. (1996). Auschwitz: Nazi death camp. Austria: Auschwitz -Birkenau State Museum.

Rhodes, R. (2003). Mestres da morte: A invenção do holocausto pela SS nazista. Rio de Janeiro: Zahar.

Roseman, M. (2003). Os nazistas e a solução final: A verdadeira história da Conferência de Wannsee. Rio de Janeiro: Zahar. 
Stern, J., \& Berger, J. M. (2015). ISIS: The state of terror. New York, NY: HarperCollins.

Stivelman, M., \& Stivelman, R. (2001). A marca dos genocídios. Rio de Janeiro: Imago.

Snyder, T. D. (2012). Terras de sangue: A Europa entre Hitler e Stalin. Rio de Janeiro: Record.

Weber, M. (1994). Economia e sociedade: Fundamentos da sociologia compreensiva. Brasília: Editora Universidade de Brasília.

Weiss, M., \& Hassan, H. (2016). ISIS: Inside the army of terror. New York, NY: Simon and Schuster.

White, M. (2013). O grande livro das coisas horriveis: A crônica definitiva história das cem piores atrocidades. Rio de Janeiro: Rocco.

Wolff, F. (2004). Quem é bárbaro. In A. Novaes (Org.), Civilização e barbárie (Vol. 177, pp. 19-43). São Paulo: Companhia das Letras.

Yürükel, S. M. (2004). The history of genocide I. Ancara: Near East Publishing.

\section{Autor}

Francis Kanashiro Meneghetti

Av. Sete de Setembro, 3165, 80230-901, Rebouças, Curitiba, PR, Brasil.

E-mail: fkmeneghetti@gmail.com 